\title{
A review on crude beeswax mismanagement and lose: opportunities for collection, processing and marketing in Ethiopia
}

\begin{abstract}
Beeswax is a valuable product that can provide a worthwhile income in addition to honey. One kilogram of beeswax is worth more than one kilogram of honey. In Ethiopia, beeswax is one of the important exportable agricultural commodities where the annual production of beeswax is estimated to be more than 5000 tons. About 64,000 tons of beeswax were produced in the world, Asia (mainly India) being the major producer with 31,000 tons. Of all honey bee products the economic importance of beeswax is second after that of honey. But in most cases it has been observed wasting. Therefore, this review paper is initiated to review the national and international resource materials, present the beeswax production and wastage in Ethiopia and other parts of the world and give recommendation for better use it. Tropical countries dominate world beeswax production and export where as the market is in developed countries. Ethiopia is among the top four beeswax producers in the world due to it's predominant traditional system of beekeeping. In some parts of the world, the valuable beeswax resource is neglected and usually wasted and the amount is very significant even though it is not properly documented. Crude beeswax is collected from three sources like local honey wine making shops, from processing companies and directly from the farmers. In every source, there is wastage due to misunderstanding of the use of beeswax in the local as well as international market. Of the total production of beeswax, the major part is utilized for the production of candle, and 'Twaf 'a candle like stick that used for church ceremony. Aware creation of stakeholders through hands on training along bees wax and honey value chain is very important. Establishment of a beeswax collection and processing centre with the accessible rendering technologies and encouraging the beekeeper to handle the beeswax resource is very important so as to save the resources. In addition to the existing information at hand, further research and development intervention from the government side including incentives is very important and timely. Introducing products traceability system and product standards is also very important.
\end{abstract}

Keywords: adulteration, beeswax, extraction, rendering
Volume 8 Issue 6 - 2018

\author{
Yeshitila Eshete, Tekeba Eshetie \\ Ethiopia Meat and Dairy Industry Development Institute, \\ Ethiopia
}

Correspondence: Tekeba Eshetie, Ethiopia Meat and Dairy Industry Development Institute, P.o.box; 1573, Bishoftu, Ethiopia, Email tyeshitela2004@yahoo.com

Received: October 25, 2018| Published: November 13, 2018

\section{Introduction}

Beeswax is the creamy colored substance used by bees to build the comb that forms the structure of their nest. The comb provides the structure of the bees home, used for all the different storage functions needed in bees nest: to store honey, to store pollen, as a place to deposit eggs and for development of the young bees. Beeswax is one of the most valuable and oldest bee products to be used by mankind ${ }^{1,2}$ and still being used in various fields of application such as cosmetics, foods, pharmaceuticals, engineering and industry. ${ }^{3}$ Beeswax is a valuable product that can provide a worthwhile income in addition to honey. One kilogram of beeswax is worth more than one kilogram of honey. Beeswax as an income generating resource is neglected in some areas of the tropics. Some countries of Africa for example Ethiopia and Angola and in other developing countries where fixed comb beekeeping is still the norm, have significant production and export of beeswax, while in others the trade is neglected and beeswax is thrown away and often wasted. But, there are many market possibilities for good quality bees wax product in local emerging markets and to the foreign market and over 150 uses of beeswax were listed and described. ${ }^{4}$ Tropical countries dominate world beeswax production and export to industrialized countries. Ethiopia is among the top four beeswax producers in the world and this is considerably attributed to the predominantly traditional system of beekeeping production, which has relatively higher beeswax product per hive. ${ }^{5}$ Worldwide, many honey hunters and beekeepers do not know that beeswax can be sold or used for locally made, high-value products. Knowledge about the value of beeswax and how to process it is often lacking. Even though It is impossible to give statistics, only half of the world production of beeswax comes on to the market, with the rest being thrown away and lost. ${ }^{6}$ Beeswax is the second most valuable product after honey however many small scale traditional beekeepers throw away wax combs on harvesting or after honey extraction. Hence, it is important to build the knowledge and skills of the beekeepers and other value chain actors how to harvest, handle, process the beeswax and enhance awareness creation on its economical importance. ${ }^{7}$ The natural composition of beeswax is a mixture of esters, fatty acids, higher alcohols and saturated hydrocarbons in addition to aromatic substances and pigments. ${ }^{8}$ Therefore, this review study is initiated so as to document the information on bees wax production and associated wastes and to give recommendation how to use it in the forth coming future. 


\section{Importance of beeswax}

\section{History of beeswax use}

Beeswax was mentioned in 32 prescriptions, given in a papyrus, compiled in Egypt about 1550 BC. It is praised for its beneficial influence on blood and energy systems and the overall balance of the body. ${ }^{9}$ Candles of beeswax were used by the ancient Egyptians, ancient Greece, Rome and in old China. It was introduced in churches since the beginning of Christianity in Europe. In the world trade beeswax is used for the cosmetics industry, pharmaceutical industry, candle making, comb foundation sheet production and used for different other purposes among others polish, grafting waxes, lubricants, electronic insulations. ${ }^{6}$ All the industries requires good quality natural beeswax wax. The average world price of beeswax usually around US\$4-10 per kilogram.

\section{Beeswax use at present}

Now a day's besides its use for comb foundations sheets to the improved beekeeping production, beeswax is used for following purposes: cosmetics 25-30, pharmacy 25-30\%, candles: $20 \%$ and other purposes: $10-20 \%$ worldwide. Beeswax is a very stable substance that resists oxidation. The composition of beeswax is very complex; the industry has not been able to produce a substitute with equal properties. ${ }^{9}$ Although many synthetic waxes are available today, beeswax remains irreplaceable in many industrial applications. ${ }^{10}$ The cosmetics and pharmaceutical industries have no complete substitute for beeswax. At least small quantities will always be needed to maintain quality and specific characteristics. ${ }^{11,12}$ Beeswax candles are less common and more expensive than candles made from paraffin wax. In the past church candles had to be made of 100 percent beeswax and this is still followed in some societies.

\section{Physical characteristics of bees wax}

Newly produced wax in the hives is clear white, but after manipulation by the bees, it soon turns pale yellow. New honeycomb is nearly white and if it is only used for honey storing it will retain its light color. This difference in color is of no significance as far as the quality of the wax is concerned, but subjectively light colored wax is more highly valued than dark colored wax. ${ }^{5}$ The structure of beeswax is crystalline and the crystallization process increases upon storage of wax until 3-4months, while at the same time, its stiffness and elasticity increase. ${ }^{13}$ Beeswax is a very stable substance, resistant to natural oxidation and insoluble in water. It is a complex material with a characteristic odor mainly derived from the bees themselves and honey, pollen or propolis. Wax is solid at room temperature and becomes brittle below $18^{\circ} \mathrm{C}$. It is soft and pliable around $35-40^{\circ} \mathrm{C}$, and melts at $64.5^{\circ} \mathrm{C} .^{14}$

\section{Composition and properties}

Beeswax is a very stable substance, and its properties change little over time. It is resistant to hydrolysis and natural oxidization and is insoluble in water. It is a complex material consisting of many different substances, but predominantly of esters of higher fatty acids and alcohols, pigments mostly from pollen and propolis, as well as minute traces of bee material. ${ }^{15,16}$ It is solid at room temperature, becomes brittle once the temperature drops below $18^{\circ} \mathrm{C}$ and quickly becomes soft and pliable at around 35 to $40^{\circ} \mathrm{C}$, with a melting point of $64.5^{\circ} \mathrm{C} .{ }^{6}$ Beeswax naturally composed of carbon, hydrogen and oxygen and has a long carbon chains of fatty acid esters and aliphatic alcohols. ${ }^{17,18}$ Beeswax is an inert material with high plasticity at a relatively low temperature (around $32^{\circ} \mathrm{c}$ ). Upon heating the physical properties of wax changed. At $30-35^{\circ} \mathrm{C}$ it becomes plastic, at $46-47 \mathrm{C}$ the structure of a hard body is destroyed and between 60 to $70^{\circ} \mathrm{C}$ it begins to melt. ${ }^{19}$ Heating to $95-105^{\circ} \mathrm{C}$ leads to formation of surface foam, while at $140^{\circ} \mathrm{C}$ the volatile fractions begin to evaporate. ${ }^{19}$ The melting point of beeswax is not constant since the composition varies slightly with its origin. Various pharmacopoeias give a range of 61$66^{\circ} \mathrm{C}$ or more commonly, $62-65^{\circ} \mathrm{C} .1^{17}$ The saponification value of beeswax is $85-100$ it is also insoluble in water, soluble in most organic solvents and resistant to many acids..$^{13}$

\section{Beeswax production}

Bees need wax as construction material for their combs. The main raw materials for wax formation are carbohydrates, honey sugars fructose, glucose and sucrose. Of all honey bee products the economic importance of beeswax is second after that of honey. The major world producer is China with an annual production of 6,000 tons. About 64,000 tons of beeswax were produced in the world, Asia (mainly India) being the major producer with 31,000 tons..$^{20}$ The raw products for wax manufacture are old combs and capping. Thus, all old combs and pieces of wax should be saved for rendering into wax blocks. Old combs should be rendered separately from newer ones since the newer combs yield a higher quality wax. Dark combs contain propolis and cocoons which lower the quality of the wax.

\section{Beeswax production potential in Ethiopia}

Small holder beekeepers are the primary sources of crude beeswax in Ethiopia. In addition, the local honey brewery industries for making "Tej" are the primary suppliers of bulk beeswax. ${ }^{2,21}$ Beeswax is collected in its "sefef" (primary residue) from 'Tej' left over and "keskes" (the partially extracted and molded one). ${ }^{1}$ Ethiopia, having a huge apicultural resources, is the leading beeswax producer in Africa, and one of the important beeswax exporter to the world. ${ }^{22}$ The average estimated annual beeswax production in Ethiopia for the last ten years is about 4,914 tons per year. The above estimate is without considering much of the beeswax produced in remote areas where it is usually wasted without harvest. Even though more wastage is estimated, in 2014 Ethiopia produced 5,344 tons of beeswax, which is $32.65 \%$ of the total beeswax produced in Africa (16,366 tons), $8.08 \%$ of the total beeswax produced globally $\left(66,173\right.$ tons). Ethiopia is $4^{\text {th }}$ in the world of raw wax production next to China, Mexico and Turkey. ${ }^{23}$ The wax yield from traditional beehives is $8-10 \%$ of the honey yield, compared to $0.5-2 \%$ from modern hives. The bulk of the supply of beeswax obtained as residual from 'Tej' production, a mild alcoholic beverage popular throughout Ethiopia. ${ }^{24,25}$ The majority of beekeepers in Ethiopia practice traditional beehives and hence, there is a potential to produce huge amount of beeswax. ${ }^{5}$ The estimated beeswax production in Ethiopia is about 4,300 tones this made Ethiopia stand first in Africa and fourth in the world. However, with the current increase in production of honey that is estimated to be around 54,000 tons the annual beeswax production is expected to be more than 5,000 tones. ${ }^{26}$ About $80 \%$ of the total Ethiopian honey production goes in to the local honey wine preparation called 'Tej'.${ }^{27}$ It is an opportunity to make use of beeswax resource out of 'Tej' leftover and to maximize the economical and social importance.

\section{Discussion}

\section{The valuable crude bees wax resource wastage}

In many parts of the world much of the beeswax produced by bees that could be harvested by beekeepers is wasted. The beeswax is left or thrown away because beekeepers do not bother to collect, 
handle and render to make a marketable beeswax blocks. ${ }^{25}$ As a result only a limited proportion, may be at most one-half, of the world's production of beeswax comes on to the market, the rest being thrown away or lost. ${ }^{2}$ Beeswax resource as an income generating business is neglected in some areas of the tropics. Some countries of Africa where fixed comb beekeeping is still the norm, among others, Ethiopia and Angola, have significant export of beeswax, while in others the trade is neglected and beeswax is thrown away. Worldwide, many honey hunters and beekeepers do not know that beeswax can be sold or used for locally made, high-value products. Knowledge about the value of beeswax and how to process it is often lacking. It is impossible to give statistics, but maybe only half of the world's production of beeswax comes on to the market, with the rest being thrown away and lost. ${ }^{6}$ In areas where most or all of the honey produced is consumed locally, and where there is no local use for beeswax, pieces of wax comb are often discarded. The development of a wax collecting system can, by encouraging each beekeeper in the area to save beeswax and by organizing the sale of the combined crop, provide a source of income from an otherwise wasted resource. Despite Ethiopia has huge potential for production of high quality beeswax, only less than $10 \%$ of the beeswax produced is exported. The beeswax production and processing practices use traditional and inefficient techniques that leave significant amount of beeswax resource unutilized. ${ }^{2}$ Field level assessment observations and other relevant information sources could indicate that, the valuable beeswax is not properly harvested, collected and handled by the beekeepers and 'Tej ' house. Knowledge about the value of beeswax and how to process it is often lacking and the large amount of crude beeswax is wasted at the beekeepers back yard and 'Tej' making house. The use of beeswax, the rendering techniques and even the existence of market demand for this product is not well known.

\section{Crude bees wax resources and opportunities for collection}

There are three sources of beeswax one is from old combs and bits of brace comb gleaned from hives during manipulation. ${ }^{18}$ The second source is from capping, at the time of honey extracting or processing the third and the major source in Ethiopian context is from the residue of 'Tej". The smallholding beekeepers are the primary sources of beeswax in Ethiopia who sell the majority of crude honey to the 'Tej' brewers. More of the marketable crude beeswax resource comes from 'Tej' houses. ${ }^{5}$ After the beverage production, the 'Tej' makers collect the crude beeswax and store it as it is in the crude form 'Sefef" or partially strained form of "Keskes". ${ }^{16}$ Traditional beeswax extractors are also the other intermediate sources who process the "Sefef" the partially strained to rough beeswax blocks. The process by which wax from combs converted into blocks of clean wax is known as rendering. ${ }^{6}$ Since whole combs are harvested and crushed or pressed, the proportion of wax per kilograms of honey $(10-15 \%)$ is much higher than with frame hive beekeeping, where the yield is only $1-2 \%{ }^{28}$ Bees Wax resource obtained from honey cappings during the honey harvest and processing are a source of the purest beeswax of high quality. ${ }^{29}$

\section{Business opportunities to collect and processing beeswax}

Beeswax is a valuable commodity and export crop and can be used as the basis of many small business activities. A simple wax collecting system and bulk selling of beeswax can result in income from an otherwise wasted resource. The beekeepers, honey hunters and the local 'Tej' makers should realize that beeswax is a valuable product.
There are many market opportunities for good quality beeswax products in local emerging markets and in import substitution. ${ }^{5}$ The production of bees wax in the European Union was 3,515 tons; an additional 6,335 tons of beeswax demand was from imported. ${ }^{11}$ The Establishment of a beeswax collection and processing centre with the locally available rendering materials and technologies is the important and recommended business promotion and job opportunity creation strategies to the local community and to develop the economical benefit of the sub sector industry. ${ }^{30}$

\section{Beeswax Rendering Technologies}

Industrial wax production began in the $19^{\text {th }}$ century. Worldwide, rendered beeswax is produced mainly by specialized beeswax manufacturers. ${ }^{19}$ Before melting and processing the crude beeswax should be washed thoroughly to remove honey and other debris. Soaking in the water for several hours, or up to two days for older brood combs. ${ }^{31}$ There are a number of different ways to process beeswax, all of which involve a combination of melting the beeswax and filtering. The hot mixture may then be squeezed out of the bag using two sticks. For additional cleaning healable water tanks from high grade steel are suitable. The wax should remain for longer time in the water bath at a temperature of $75-80^{\circ} \mathrm{C}$ (best over night). ${ }^{9}$ The wax recovery depends on the quality of the crude beeswax resource and on the method of rendering used. Generally, recovery from old combs is around $50 \%$. If more cappings and new combs are used it could be higher. All methods of rendering involve melting the wax with water. The wax recovery depends on the combs and on the method used. If more cappings and new combs are used it could be higher. ${ }^{19}$ Beeswax never is heated with a direct flame: always heat it in a container of water. This water bath might be an oil drum or other large container. Heat the wax enough to melt it: beeswax melts at $62-64^{\circ} \mathrm{C}$. Heating above $85^{\circ} \mathrm{C}$ causes discoloration of the wax, and boiling will ruin it. ${ }^{6}$ Direct exposure of wax to hot steam results in partial saponification and discoloration. ${ }^{9,32}$ Beeswax may be heated in a double boiler or commercial wax melter following standard safety recommendations. The liquid wax may be poured through the simple filter to remove bits of dirt and hive contamination that naturally occurs in the hive. This process may need to be repeated more than once, depending on the use of the wax. ${ }^{17}$

\section{Beeswax quality requirements}

Beeswax is valued according to its purity and sometimes its color light wax (from new combs) is often more highly valued than dark wax (from old combs). ${ }^{7,33}$ The presence of pollen, propolis and impurities can cause the beeswax to become yellow., ${ }^{3,34}$ It will also darken with age so it is better used or sold as quickly as possible. Beeswax is an extremely complex material containing over 300 different substances. ${ }^{35}$ In addition, approx. 50 aroma components have been identified. ${ }^{36}$ When paraffin wax is mixed with beeswax, it becomes more transparent and slightly greasy to the touch. The bright color of wax is more appreciated than dark-colored wax. ${ }^{3}$ The composition of beeswax depends on the content of paraffin hydrocarbons, free fatty acids, esters of fatty acids and fatty alcohols. Presently, because of its high demand and shortage in the world market, it's adulteration with cheaper materials became a challenge for its quality and marketing. On the other hand the deterioration of beeswax's natural quality and the alteration of its composition as a result of prolonged over heating during rendering have been reported. ${ }^{33}$ The authenticity of beeswax can be determined by using physical-chemical parameters, such as melting point, density, acid value, saponification value, ration number, ester value, iodine absorption number, and peroxide value. ${ }^{37}$ 
Color does not affect the quality of the wax, unless it is dark from over-heating. Under local conditions deterioration of beeswax quality due to overheating from processing is highly likely to happen; some of the processing facilities are not suitable to regulate the optimum temperature during processing. ${ }^{11}$ Even though, Ethiopia has developed the beeswax quality standards, setting marketing and quality regulation legal frame work and assigning the relevant administration and regulatory body is still on process. Longer heating or higher temperatures lead to greater quality degradation and loss of hydrocarbons. ${ }^{34}$ In industrialized countries, the widespread use of chemicals in beekeeping and subsequent contamination of beeswax makes the beeswax harvested from disease-free colonies in Africa and other regions more precious and valuable. ${ }^{38}$ The main quality issues concern authenticity of origin, and contamination from residues of drugs used to control honeybee diseases, mainly the acaricides used to control mite predators. These acaricides are lipophyllic and therefore are soluble in beeswax, and accumulate in it. The contamination of beeswax can be minimized by avoiding the use of chemicals in beekeeping. The use of these chemicals in beekeeping in industrialized countries makes beeswax harvested from the disease-free colonies of Africa and other developing regions more attractive. ${ }^{6}$

\section{Adulteration}

Beeswax is relatively expensive, and there has always been a tendency for people to try to falsify or dilute it with cheaper materials. The melting point of pure beeswax is $64.5^{\circ} \mathrm{C}$, and adulteration of pure beeswax with paraffin wax reduces the melting point and weakens the material. The adulteration of beeswax with cheaper materials like animal fats, plant oils and paraffin has become a national and international problem. It has a great influence on quality assurance and its marketing. ${ }^{5}$ To detect adulteration, a number of tests may have to be conducted. The simplest test is to determine the melting point by measuring the temperature at which the first liquid wax appears during very slow heating. It should be between 61 and $66^{\circ} \mathrm{C}$ or preferably between 62 and $65^{\circ} \mathrm{C}$. Beeswax samples adulterated with $1 \%$ animal tallow melted at slightly lower temperature at an average of $61^{\circ} \mathrm{C}$, which was lower by $1^{\circ} \mathrm{C}$ than the lower limit of most pure beeswax melting point standards. ${ }^{11}$ Adulteration with paraffin wax depresses the melting point $\left(64.5^{\circ} \mathrm{C}\right)$ and weakens the material.

\section{Market demand}

The world production of around 60,000 metric tons of beeswax has multiple uses. The EU imports around 6,000 tons of beeswax per annum, approximately 50 percent of this coming from developing countries. Tropical countries dominate world beeswax production and export, with industrialized countries needing to import beeswax. ${ }^{6,18}$ Because of its high demand and shortage in the world market, adulteration of beeswax with cheaper materials has been a challenge to sustain in the existing market and to access new market.

\section{Beeswax marketing and trade in Ethiopia}

Beeswax is one of the primary exportable agricultural products of Ethiopia. ${ }^{26}$ The country has been well known in beeswax trade for a long time and is one of the four biggest wax exporters to the world market amounting to on average about 347 tons per year with increasing trend from time to time. This demonstrates that less than $10 \%$ of the total estimated beeswax production of the country is exported. The remaining larger portion of it is either used in local market and or wasted. ${ }^{23}$ Beeswax Exports from Ethiopia have increased and reached 402 tons $(1.2 \%$ share in world market), destination to different countries (USA, Japan, Greece, Great Britain and Netherlands etc.).
Beeswax from Ethiopia has higher demand and also earns higher price in EU, that is mainly used for blending low quality beeswax from different sources. ${ }^{5}$ The crude beeswax resource marketing and supply system is a pattern of fragmented distribution channels and supply chain, it cause a significant challenge to traceability. In the domestic market, farmers either sell directly or through middlemen, collectors and suppliers. ${ }^{33}$ The export trend of beeswax from Ethiopia is summarized as follows in Figure 1. The average annual beeswax export from Ethiopia to different destination countries was about 365 tons. Based on the CSA 2017/2018 data Ethiopia produce about 47,710 tons of crude honey the estimated beeswax product with the proportion 8 percent could be about 3816.8 tons. On the same year Ethiopia export about 302.34 tons of beeswax which is about 8 percent of the total production. Even though, it is difficult to have the exact data of beeswax consumption locally to Candle and "Tuwaf" making, and to make foundation sheets to the improved beekeeping, lose of huge amount of beeswax is undeniable fact. ${ }^{39,40}$

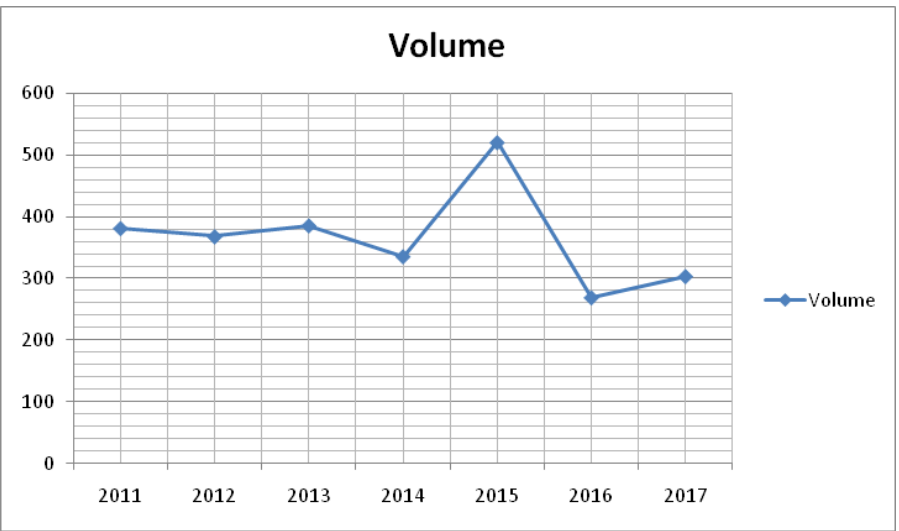

Figure I Ethiopian Bees wax export data from 20 I I-20I7 in tons.

\section{Conclusion}

Beeswax is one of the important exportable agricultural commodities in the international market. Because of its pliability, yellow coloration and other physical properties. The Ethiopian beeswax has been highly demanded and mostly used to blend beeswaxes from other sources. Despite Ethiopia has huge potential for production of high quality beeswax, only less than $10 \%$ of the beeswax produced is exported. Beeswax as an income generating resource is neglected in some areas of the tropics. Some countries of Africa where fixed comb beekeeping is still the norm, for example, Ethiopia and Angola, have significant export of beeswax, while in others the trade is neglected and beeswax is thrown away and wasted. Knowledge about the value of beeswax and how to process it is often lacking. Due to this fact, large amount of crude beeswax is wasted at the beekeepers back yard and 'Tej' making houses. Awareness creation on the economical value and importance of the beeswax, developing the knowledge and skills on the handling and rendering techniques and communicating the existence of market demand for this product along all the value chain is important. Similarly, introduction and adoption improved processing techniques and technologies of higher efficiency are to be important interventions to be taken to increase the production and productivity of the beeswax. Establishment of beeswax collection center and put in place the marketing legal framework that have clear path of the products movements in the market is important to assure the quality, to minimize the problem of adulteration and to develop traceability system. 


\section{Recommendations}

Developing the knowledge and skills of the beekeepers, the local 'Teji' makers and all other value chain actors on the valuable beeswax resource collecting, handling, processing, quality assurance and marketing are the areas needs stringent attention and intervention strategies. Establishment of the beeswax collection and processing centers in particular at beeswax resources potential areas of the country and developing awareness creation on the economical importance of valuable beeswax resource is the important. Recommended business promotion and job opportunity creation strategies to the local community and to enhance the economical benefit of the sub sector will increase the use of bees wax in it's natural form. Put in place and functionalize the quality administration, quality control and market chain system regulation and set up a clear path of the products movements in the market chain. It is also important and a must to introduce a traceability system to reduce the problem of adulteration and other frauds. Further research and development efforts and incentive mechanisms from the government side is very important to uplift the sub-sector from its current staggering phase to globally competitive agri-business.

\section{Acknowledgements}

None.

\section{Conflict of interest}

The authors declare that there is no conflict of interest.

\section{References}

1. Nuru. Physical and Chemical Properties of Ethiopian Beeswax and Detection of Adulteration. Ethiopian Journal of Animal Production (EJAP). 2007;7(1):39-48.

2. Ayalew. Honey and Beeswax Value Chain of BOAM Programme. Establishment of Apiculture Data Base in Ethiopia. SNV Netherlands Development Organization. Addis Ababa, Ethiopia. 2008. Markets in Germany, the United Kingdom, and the Netherlands.

3. MAAREC. Beeswax. Mid Atlantic Apicultural Research and Extension Consortium (MAAREC). 2005;3(9):1-5.

4. Adjare. The golden insect, A handbook on beekeeping for beginners. IT Publications, Nottingham, UK: Russell Press Ltd; 1984. 104 p.

5. Gemechis. Beeswax Production and Marketing in Ethiopia: Challenges in Value Chain. Agriculture, Forestry and Fisheries. 2014;3(6):447-451.

6. Bradbear. Production and trade of beeswax. In: Bees and their role in forest livelihoods. Chapter 10. Rome, Italy: FAO; 2009.

7. Nicholas. National Bee Keeping Training and Extension Manual, Uganda. In: Reich AG, Waylett DK, van der Riet, BE, Doyle E, editors. 1997. Intake of naturally occurring alkanes. Unpublished report; 2012.

8. Ghanem. The antimicrobial activity of some honeybee products and some Saudi folkloric plant extracts. Journal of King Abdulaziz University-Science. 2011;23(2):47-62.

9. Bogdanov S. Bee Product Science, Beeswax production, properties, composition control, 123 PUBLICATIONS 5,635 CITATIONS. Switzerland: Muehlethurnen; 2016.

10. Van Loon M, Jan Koekoek F. Export Opportunities for African Organic Honey and Beeswax survey. 2006.

11. Krell. Value added products from beekeeping Agricultural Services Bulletin No 124. Food and Agriculture Organization of the United Nations: Rome, Italy; 1996.
12. Basa B, Belay W, Tilahun A, et al. Review on Medicinal Value of Honeybee Products: Apitherapy. 2016;10(4):236-247.

13. Smith, 1951. Preliminary report on Trigona wax. E. Afr Agric J. 16 (4):185-187.

14. Bradbear. Bees for Development Journal. 2016. 121 p.

15. Bogdanov S. Propolis: Composition, Health, Medicine: A Review. Bee Product Science. 2015:1-40.

16. Bogdanov S. Royal Jelly, Bee Brood: Composition, Health, Medicine: A Review. Bee Product Science. 2015:1-35.

17. Larry C. American bee journal, Beeswax How Bees Use Beeswax in the Beehive. American Bee Journal. 2015.

18. Marieke M, Blitterswijk H, Leven L, et al. Bee products properties, processing and marketing. agrodoc. 2005;42:43-51.

19. Bogdanov S. Beeswax: Composition and Control. Beeswax Book. 2016. $118 \mathrm{p}$.

20. FAO. Rural Infrastructure and Agro-Industries Division, Rome. 2011.

21. Beyene. Ensuring Small Scale Producers in Ethiopia to Achieve Sustainable and Fair Access to Honey Markets, (April). 2005.

22. Tessega B. Honeybee production and marketing systems: Constraints and opportunities in Burie District of Amhara Region, Ethiopia. MSc Thesis, Bahir Dar University. Bahirdar, Ethiopia. 2009. 116 p.

23. Dayanandan R. Opportunities and Challenges of Apiculture in Ethiopia. SCHOLARS WORLD-IRMJCR. 2015;3(1):5-24.

24. Johannes A. Strategic intervention plan on honey \& beeswax value chains. SNV support to Business Organizations and their Access to Markets (BOAM). 2005. 37 p.

25. Fichtl R, Admasu A. Honeybee Flora of Ethiopia. Margraf Verlag, Weikersheim, Germany. 1994. 510 p.

26. FAOSTAT. FAOSTAT data. Statistical Database. Livestock Primary. 2016.

27. Hartmann I. No Tree, No Bee, No Honey, No Money: The Management of Resources and Marginalisation in Beekeeping Societies of South West Ethiopia. Briding Scales and Epistemologies, Alexandria. 2004:1-12.

28. Gezahegn. Strategic options for quality improvement of Ethiopian beeswax exports. 2006 .

29. Leenvan 't L, Jan Boot W, Mutsaers M, et al. Beekeeping in the tropics. Agrodok-series No. 2005;32:69-70.

30. Brown RH. Beeswax Bee Books: New and Old; 1981.

31. Crane E. Bees and beekeeping: science, practice and world resources. Heinnmann Newness, London. 1990. 614 p.

32. Graham JM. The hive and the honeybee. USA: Dadant \& Sons, Hamilton, Illinois; $1992.1324 \mathrm{p}$.

33. Bogdanov S. Quality and standards of pollen and beeswax. Apiacta. 2004;38:334-341.

34. Bogdanov S. Beeswax: quality issues today. Bee World. 2004;85(3):4650

35. Tulloch AP. Beeswax - composition and analysis. Bee World. 1980;61(2):47-62.

36. Ferber CEM, Nursten HE. The aroma of beeswax. J Sci Fd Agric. 1977;28(6):511-518.

37. Bernal JL, Jimenez JJ, Jesus del Nozal M, et al, Physico-chemical parameters for the characterization of pure beeswax and detection of adulterations. European Journal of Lipid Science and Technology. 2005; 107:158-166 
38. Bogdanov S. Contaminants of bee products. Apidologie, Springer Verlag. 2006;37(1):1-18.

39. EFSA. Scientific Opinion of the Panel on Food additives, Flavourings, Processing aids and Materials in Contact with Food (AFC). EFSA Journal. 2007;615:1-28.
40. Bogdanov S. Beeswax: History, Uses and Trade. Beeswax Book, 2016:1- 